\title{
Short-Term Creep Experiment of Cement Asphalt Mortar and Its Numerical Simulation
}

\author{
Hao Xu, ${ }^{1}$ Ping Wang, ${ }^{2}$ Hong-song Lin, ${ }^{1}$ and Hua Yan' \\ ${ }^{1}$ China Railway Eryuan Engineering Group Co., Ltd., Chengdu 610031, China \\ ${ }^{2}$ Key Laboratory of High-Speed Railway Engineering, Southwest Jiaotong University, Ministry of Education, Chengdu 610031, China
}

Correspondence should be addressed to Hao Xu; xhao0@163.com

Received 8 October 2015; Revised 16 February 2016; Accepted 16 March 2016

Academic Editor: Donato Sorgente

Copyright (C) 2016 Hao Xu et al. This is an open access article distributed under the Creative Commons Attribution License, which permits unrestricted use, distribution, and reproduction in any medium, provided the original work is properly cited.

In order to investigate the creep performance of cement asphalt mortar (CA mortar), the field sampling of CA mortar cylinder samples was produced, and all samples were tested on WDW series electric universal testing machine by using uniaxial static creep test at $25^{\circ} \mathrm{C}$, and the load stress levels were $0.05 \mathrm{MPa}, 0.1 \mathrm{MPa}, 0.3 \mathrm{MPa}$, and $0.5 \mathrm{MPa}$. The greater the load is, the bigger the creep deformation is. The creep performance was simulated by using Burgers model, and the correlation coefficients between fitting results of Burgers model and experimental results are all greater than 0.9. Based on the requirements of finite element software, the Prony series of Burgers model was obtained, and the short-term creep process of CA mortar was simulated by the finite element software ANSYS. The relative error between simulation results and experimental data is not more than $2.5 \%$, which indicates that the short-creep process of CA mortar can be simulated by ANSYS software. The study results can improve the structural design theory of slab track.

\section{Introduction}

The nonballast slab track consists of concrete roadbed, reinforced concrete track slab, and cement asphalt mortar (CA mortar) injected between the roadbed and track slab [1]. With the rapid development of high-speed railway, cement and asphalt mortar (CA mortar) which is the key material of the cushion layer of ballastless slab track is widely used in high-speed railways in Japan [2, 3], Germany, France, and China [4], and it consists of cement, emulsified asphalt, fine aggregates, water, and admixtures and is an organicinorganic composite material formed by mechanical mixing, whose main functions are supporting and adjustment, buffer and load transfer, blocking cracking, and providing elasticity and resistance for track structure [5]. CA mortar is very important for the safety, stability, and comfortable degree of high-speed railway [6].

As a viscoelastic material and in order to meet its service environment and construction conditions, the physical and chemical properties of CA mortar and mechanical properties have been studied extensively [7-13]. Wang et al. [7] investigated the compressive strength developing process and the microstructure of CA mortar. Yutaka et al. [8] introduce the CA mortar used in cold weather, and Kazuyosi and Yosio [9] and Wang et al. [10] studied the compressive strength of CA mortar and its temperature susceptibility. Liu et al. [11] studied the static and dynamic mechanical properties of CA mortar. Qiu et al. [12] studied the fatigue behavior of $\mathrm{CA}$ mortar and proposed the fatigue equation. $\mathrm{Xu}$ et al. [13] investigated the dynamic compression damage properties of CA mortar under different strain rates. These research results play a useful guiding role in actual projects. Creep property is an important index for evaluating the viscoelastic behavior of CA mortar, and according to survey, after the high-speed railway has been operated for 3-5 years, the CA mortar layer will have unrecoverable deformation. Therefore, the study on the creep properties of CA mortar is very necessary.

Creep is the case that the deformation of material increases with the growth of time at constant load. Uniaxial static load creep test is one of the principal methods of studying material viscoelastic properties. Xie et al. [5] studied the long-term deformation properties and creep properties of CA mortar. Li and Jiang [14] conducted uniaxial creep test of asphaltic sand under 6 loading stresses at $20^{\circ} \mathrm{C}$, and the results showed that the Burgers model can reflect asphaltic sand's viscoelasticity well. Guo and Zhao [15] studied the effects of fiber 

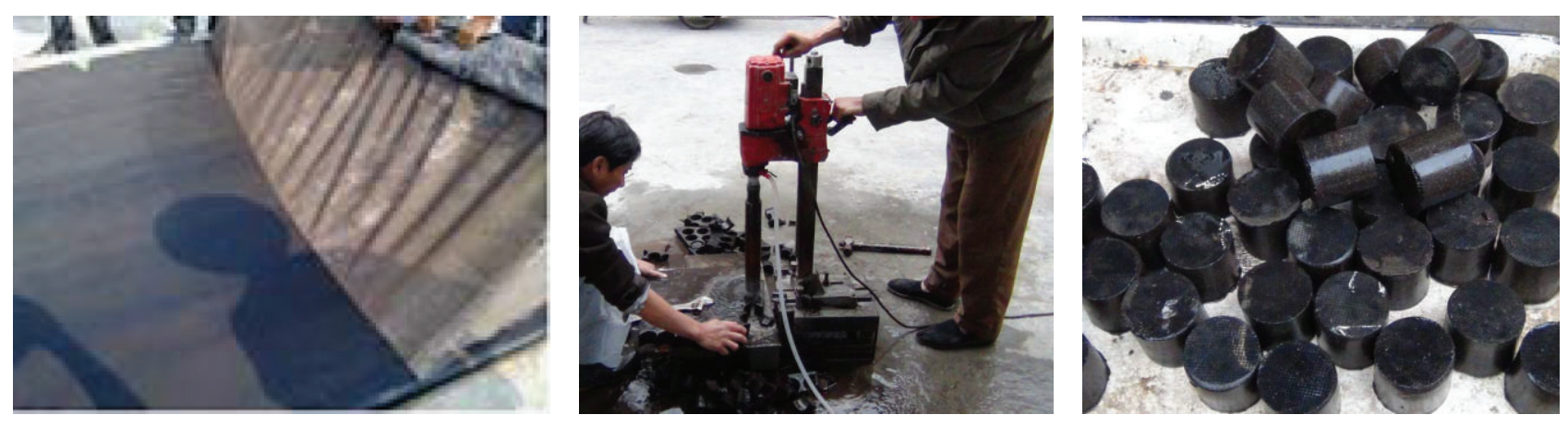

FIGURE 1: Sampling process and part specimens.

content on the creep performance of fiber reinforced asphalt concrete by using uniaxial creep test, and the reasonable fiber content is $0.2 \%$.

As the buffer, damping structural layer of slab track, CA mortar is mainly under the vertical load and in dynamic loading process [16], so the short-term creep properties are also needed to be researched. In this work, the relationship between deformation of CA mortar and time was measured under uniaxial static load through uniaxial compression creep test. The creep properties of CA mortar under different stress level were studied, and the test curve was fitted, which could provide an experimental basis for the optimization of CA mortar and design of slab track.

\section{Experimental}

2.1. Raw Materials and Specimen Fabricating. In order to reflect the mechanical properties of CA mortar in field CRTS I type slab track, the CA mortar specimens used in this experiment were sampled in the construction field. The lift plate test of field CA mortar layer of CRTS I type slab track was conducted firstly. And then, core samples were taken on the CA mortar layer. Specimens are cylinder specimens with the size of $\varphi 50 \times 50 \mathrm{~mm}$. Sampling process and part specimens of CA mortar layer are shown in Figure 1.

The raw materials of CA mortar field specimens come from Anhui Engineering Material Technology Co., Ltd., of CTCE Group. The $24 \mathrm{~h}$ volume expansion rate of these cement emulsified asphalt mortar special dry ingredients is $2.1 \%$, whose $7 \mathrm{~d}$ line expansion rate is $0.1 \%$ and the $1 \mathrm{~d}$ compressive strength is $6.89 \mathrm{MPa}$. The asphalt emulsion is the special emulsified asphalt of CA mortar on CRTS I type slab ballastless track, whose solid mass fraction is $62.1 \%$. Average strength of CA mortar specimens is $2.63 \mathrm{MPa}$ and the elasticity modulus is $269.58 \mathrm{MPa}$. Other properties meet the Chinese regulation [17] put in references. The mix proportion of CA mortar is $m$ (dry ingredients) $: m$ (asphalt) $: m$ (water) $=$ 1000:500:60. Mixing water is tap water. The age of CA mortar used in the creep test is $180 \mathrm{~d}$.

2.2. Experimental Method. The experiment was conducted by WDW series microcomputer electronic universal testing machine, and this machine was controlled by computer, driven by a servomotor, and loaded by precision ball screw machine. There is load sensor in the compressive direction. The displacement was measured by high precision displacement sensor. The accuracy of this experiment machine can reach to $10^{-3} \mathrm{~mm}$. This machine has the advantages of stable loading, accurate measurement, and the machine can collect load and displacement data automatically.

The creep test of CA mortar is conducted by uniaxial compressive creep test. According to the stress of CA mortar in actual engineering which is $0.1 \mathrm{MPa}$ [18], considering the deterioration of track irregularity and the disease of CA mortar, when the debonding length of CA mortar varies from $0.0 \mathrm{~m}$ to $1.0 \mathrm{~m}$, the stress of CA mortar varies from $0.057 \mathrm{MPa}$ to $0.53 \mathrm{MPa}$ [19]. Short-creep properties of CRTS I type slab ballastless track were studied, respectively, at 4 load levels (0.05 MPa, 0.1 MPa, 0.3 MPa, and 0.5 MPa). The experimental temperature was controlled in $23 \pm 2^{\circ} \mathrm{C}$. The experimental process is first preload $(0.005 \mathrm{MPa}) 10 \mathrm{~min}$ and then applied to the required load moment and kept in $60 \mathrm{~min}$, and then the experiment is ended. The deformation measurement is the key point in a creep test. The creep deformation was collected automatically by the electronic universal testing machine, which can ensure the reliability and accuracy of data to measure. There were 3 specimens in each group, and the final result was the average deformation of 3 specimens. Two loading surfaces were coated with French chalk to reduce the surface restraint effect and three samples were used for each test as duplication. If test results are discrete, the number of specimens should be increased in order to ensure the validity of test data.

\section{Results and Analysis}

According to test results, the average values of the test results are listed in the same coordinate system. Creep curves of CA mortar under different load level are shown in Figure 2.

As shown in Figure 2, the shapes of creep curves of CA mortar are similar under different load level. CA mortar can be seen as three-phase system: asphalt, cement gel, and fine aggregates. In the beginning of the three-phase system of CA mortar bearing the load together, with the passage of time, the asphalt gradually unloads due to viscous flow, and the cement gel and fine aggregates bear more load and have elastic deformation [5]. Under the action of instantaneous load, CA mortar produces the instantaneous deformation, and 


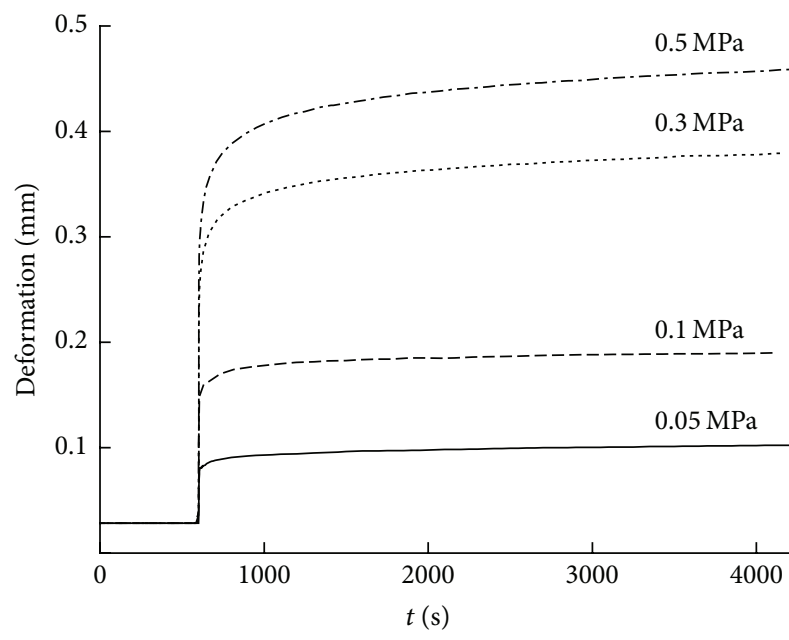

Figure 2: Creep curves of CA mortar under different load level.

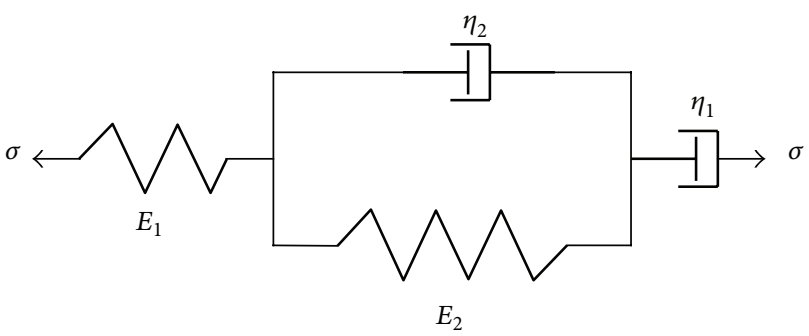

FIgURE 3: Schematic diagram of Burgers model.

the deformation increases sharply. With the sustaining action of a constant load, the deformation of CA mortar increases, and the final incremental deformation is gradually stabilized. This stage of deformation is called delayed elastic deformation, and then CA mortar shows a viscous flow gradually. The higher the load level is, the larger the creep deformation of CA mortar is. When the load stress is $0.05 \mathrm{MPa}$, the creep deformation of CA mortar is $0.074 \mathrm{~mm}$. When the load stress is $0.5 \mathrm{MPa}$, the creep deformation is $0.431 \mathrm{~mm}$. The creep deformation of CA mortar increases by 5.82 times when the load stress varies from $0.05 \mathrm{MPa}$ to $0.5 \mathrm{MPa}$.

\section{Creep Model}

Viscoelasticity material can be described by an appropriate mathematical model, and the basic components used to describe the viscoelastic properties are hook springs and Newton sticky pot. There are viscoelastic models: Maxwell model, Kelvin model, Burgers model, and generalized Maxwell model used in engineering, and the Burgers model could reflect the creep and relaxation properties. In this paper, the Burgers model was selected to describe the creep property of CA mortar.

4.1. Creep Model and Constitutive Equations. Burgers model consists of two hook springs and two Newton sticky pots. The Burgers model was shown in Figure 3.

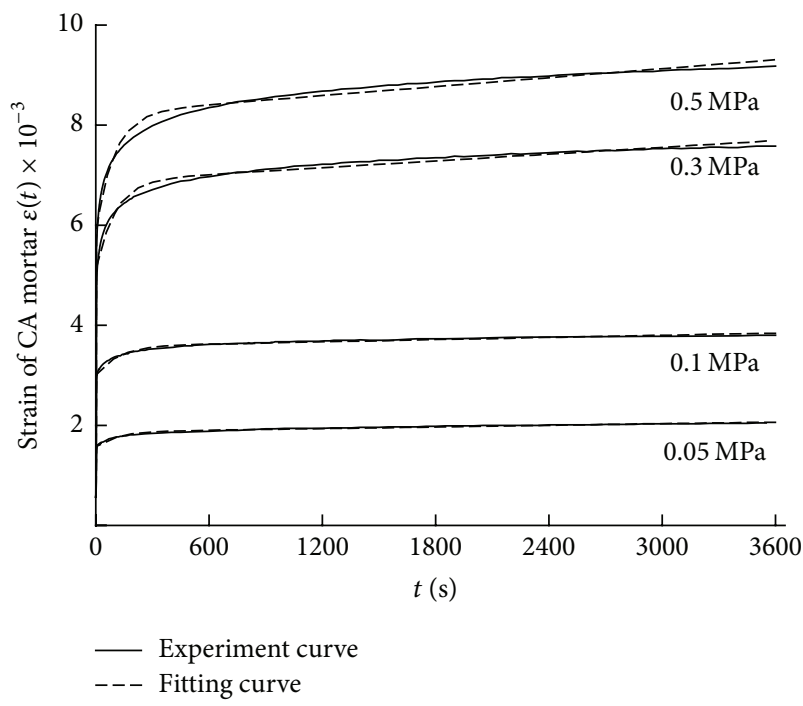

FIGURE 4: Fitting curves of Burgers model and experimental curves of CA mortar.

Burgers model is four-parameter fluid model and its constitutive relation can be expressed as

$$
\sigma+p_{1} \dot{\sigma}+p_{2} \ddot{\sigma}=q_{1} \dot{\varepsilon}+q_{2} \ddot{\varepsilon} .
$$

Here, $p_{1}=\eta_{1} / E_{1}+\left(\eta_{1}+\eta_{2}\right) / E_{2}, p_{2}=\eta_{1} \eta_{2} / E_{1} E_{2}, q_{1}=\eta_{1}$, and $q_{2}=\eta_{1} \eta_{2} / E_{2}$.

The creep compliance can be obtained by formula (1), which can be expressed as

$$
J(t)=\frac{1}{E_{1}}+\frac{t}{\eta_{1}}+\frac{1}{E_{2}}\left(1-e^{-E_{2} t / \eta_{2}}\right) .
$$

For the Burgers model, the total deformation of CA mortar under stress of $\sigma=\sigma_{0} H(t)$ is

$$
\varepsilon(t)=\sigma_{0}\left[\frac{1}{E_{1}}+\frac{t}{\eta_{1}}+\frac{1}{E_{2}}\left(1-e^{-E_{2} t / \eta_{2}}\right)\right] .
$$

Here, $E_{1}, \eta_{1}, \eta_{2}$, and $E_{2}$ are model parameters, $t$ is the experiment time, and $\sigma_{0}$ is the loading stress.

4.2. Parameters Calculation of Creep Model. The viscoelastic parameters of the model are determined by mathematical iteration method. According to the creep test data, the nonlinear fitting method was provided by Origin software. The initial parameters are assumed and the parameters of the model are obtained by the given function expression.

It is assumed that the initial values of Burgers model parameters $E_{1}, \eta_{1}, E_{2}$, and $\eta_{2}$ are $120,5 e^{5}, 60$, and $7 e^{3}$, the fitted parameters of CA mortar under different stress level are shown in Table 1, and the fitted results are shown in Figure 4.

As shown in Table 1 and Figure 4, the Burgers model can effectively predict the short-term creep of CA mortar under different load level.

For the Burgers model, elastic parameter $E_{1}$ determines the initial position in the creep process, which reflects 
TABLE 1: Parameters of Burgers model.

\begin{tabular}{lccccc}
\hline \multirow{2}{*}{ Load level/MPa } & \multicolumn{2}{c}{ Model parameters } & \multicolumn{2}{c}{ Correlation coefficient } \\
\hline 0.05 & $E_{1} / \mathrm{MPa}$ & $\eta_{1} /\left(10^{5} \mathrm{MPa} \cdot \mathrm{s}\right)$ & $E_{2} / \mathrm{MPa}$ & $\eta_{2} /\left(10^{4} \mathrm{MPa} \cdot \mathrm{s}\right)$ & 0.981 \\
0.1 & 31.957 & 9.289 & 163.123 & 1.782 & 0.974 \\
0.3 & 33.326 & 13.68 & 172.126 & 1.958 & 0.987 \\
0.5 & 58.862 & 13.295 & 168.315 & 2.09 & 0.989 \\
\hline
\end{tabular}

TABle 2: The Prony series of Burgers model parameters.

\begin{tabular}{lcccc}
\hline \multirow{2}{*}{ Load stress/MPa } & \multicolumn{4}{c}{ Prony series of Burgers model } \\
& $g_{1}$ & $g_{2}$ & $\tau_{1}$ & $\tau_{2}$ \\
\hline 0.1 & 0.1628 & 0.8371 & 95.303 & 49016.136 \\
\hline
\end{tabular}

the ability to resist deformation of CA mortar. Elastic parameter $E_{2}$ determines the value of delayed elastic deformation of CA mortar, viscosity parameter $\eta_{1}$ influences the curve slope of viscous flow deformation, and viscosity parameter $\eta_{2}$ controls the bending extent of the delayed elastic deformation curve.

4.3. Simulation of CA Mortar Creep Process. The mechanical parameters of material are required by the Prony series when calculating the viscoelastic mechanics using the ANSYS finite element software. According to [20], the shear modulus of the Burgers model can be expressed as Prony series as follows:

$$
G(t)=G_{\infty}+G_{0}\left(g_{1} e^{-t / \tau_{1}}+g_{2} e^{-t / \tau_{2}}\right) .
$$

Here, $G_{\infty}=0, G_{0}=G_{1}, g_{1}=(1 /(\alpha-\beta))\left(G_{2} / n_{2}-\beta\right)$, $g_{2}=(1 /(\alpha-\beta))\left(\alpha-G_{2} / n_{2}\right), \tau_{1}=1 / \beta, \tau_{2}=1 / \alpha$, and $n_{2}=\eta_{2} / 3$, where $g_{1}, g_{2}, \tau_{1}$, and $\tau_{2}$ are the coefficients needed to be entered, which correspond to the ANSYS software in the specified Prony series, respectively. And $E_{1}, \mu$ are the initial elastic modulus and Poisson's ratio.

Since the stress of CA mortar is $0.1 \mathrm{MPa}$ in actual engineering [18], the Burgers model parameters under $0.1 \mathrm{MPa}$ were put into the formula above, and the Prony series $g_{1}, g_{2}$, $\tau_{1}$, and $\tau_{2}$ of Burgers model needed to be entered in ANSYS software are shown in Table 2.

In order to calculate simply, the model is a rectangle with size $1 \mathrm{~m} \times 2 \mathrm{~m} \times 1 \mathrm{~m}$, and the size of an element is $1 \mathrm{~m} \times 1 \mathrm{~m} \times$ $1 \mathrm{~m}$. The calculation model of ANSYS software is shown in Figure 5 . The calculation model was simulated by solid 185 , which has the properties of super elasticity, stress toughened, creep, large deformation, and large strain. The model has two elements, and the axial uniformly distributed load $p=$ $100 \mathrm{kN} / \mathrm{m}^{2}$. According to the element area, the stress of each unit is $0.1 \mathrm{MPa}$, and the load time is $3600 \mathrm{~s}$. The axial strain of unit 1 was chosen as a comparative data. Creep test data, fitting data, and ANSYS calculation results are compared in Table 3.

As shown in Table 3, the relative error of creep experimental data of CA mortar and fitting data is less than $1.7 \%$, and the relative error and ANSYS calculation results are below $2.5 \%$. The short-term creep process of viscoelastic material

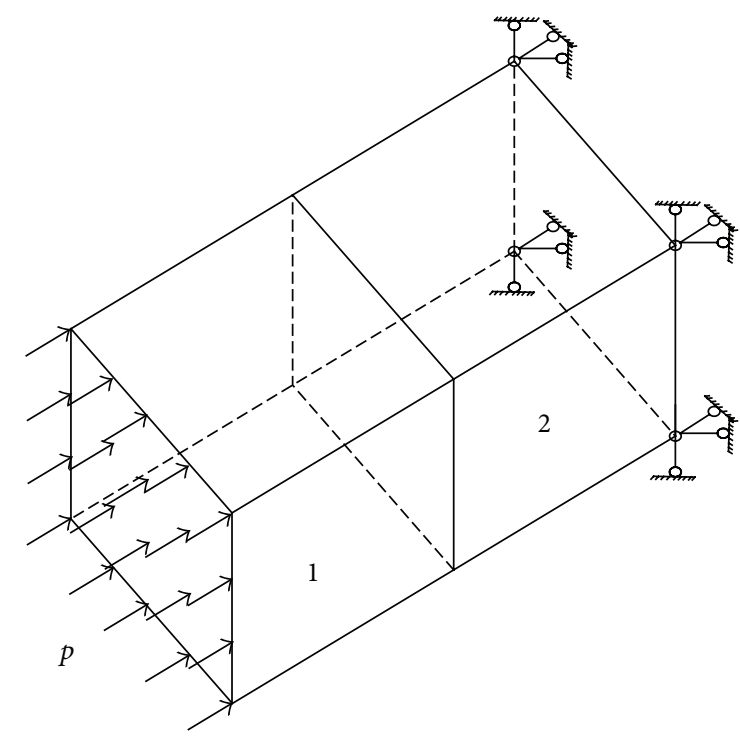

FIgURE 5: Calculation model of ANSYS.

can be simulated using ANSYS software. The differences between test data, fitting data, and ANSYS calculation results are mainly due to the error of fitting and viscoelastic parameters transform to Prony series.

\section{Conclusions}

The short-term creep properties of CA mortar were studied by the independently uniaxial static creep experiment, the creep properties of CA mortar were fitted by Burgers model, and the short-term creep process was simulated by ANSYS software. The following conclusions can be drawn:

(1) CA mortar as a typical viscoelastic material has obvious creep characteristics, the shapes of creep curves of CA mortar are similar under different load level, and the higher the load level is, the larger the creep deformation of CA mortar is. When the load level reaches $0.5 \mathrm{MPa}$, the creep deformation is $0.431 \mathrm{~mm}$; compared to the creep deformation under the load level $0.05 \mathrm{MPa}$, the creep deformation of CA mortar increases by 5.82 times.

(2) A creep constitutive model of CA mortar based on the Burgers model is established. The model has a simple form and can predict the short-term creep deformation of CA mortar, and the correlation coefficients of 
TABLE 3: Compared with the result of creep test, fitting data, and ANSYS calculated.

\begin{tabular}{lccccc}
\hline \multirow{2}{*}{ Time/s } & Test data (strain) & \multicolumn{2}{c}{ Fitting data of Burgers model } & \multicolumn{2}{c}{ Calculation results of ANSYS } \\
& & Total strain & Relative error & Total strain & 0.00308 \\
Relative error
\end{tabular}

the creep constitutive model of CA mortar are more than 0.9 .

(3) The short-term creep process of viscoelastic material can be simulated using ANSYS software. And the differences between test data, fitting data, and ANSYS calculation results are mainly due to the error of fitting and viscoelastic parameters transformed to the Prony series. Meanwhile, the application of the creep model to describe the creep properties of CA mortar under high-speed vehicle load needs to be further studied.

\section{Competing Interests}

The authors declare that they have no competing interests regarding the publication of this paper.

\section{References}

[1] E. Coenraad, "Recent development in slab track," European Railway Review, vol. 9, no. 2, pp. 81-85, 2003.

[2] O. Murata, "Overview of recent structure technology R \& D at RTRI," Quarterly Report of RTRI, vol. 44, no. 4, pp. 133-135, 2003.

[3] Y. Koyama, "Railway construction in Japan," Japan Railway and Transportation Review, vol. 12, no. 2, pp. 36-41, 1997.

[4] F.-Z. Wang, Z.-C. Liu, T. Wang, and S.-G. Hu, "A novel method to evaluate the setting process of cement and asphalt emulsion in CA mortar," Materials and Structures, vol. 41, no. 4, pp. 643647,2008

[5] Y.-J. Xie, Q. Fu, G.-C. Long, K.-R. Zheng, and H. Song, "Creep properties of cement and asphalt mortar," Construction and Building Materials, vol. 70, pp. 9-16, 2014.

[6] W. Qiang, Y. Peiyu, A. Ruhan, Y. Jinbo, and K. Xiangming, "Strength mechanism of cement-asphalt mortar," Journal of Materials in Civil Engineering, vol. 23, no. 9, pp. 1353-1359, 2011.

[7] Q. Wang, P.-Y. Yan, X.-M. Kong, and J.-B. Yang, "Compressive strength development and microstructure of cement-asphalt mortar," Journal of Wuhan University of Technology (Materials Science Edition), no. 9, pp. 998-1003, 2011.

[8] H. Yutaka, T. Seiichi, and I. Noriyuki, "Development of cementasphalt mortar for slab tracks in cold climate," Quarterly Report of RITI, vol. 22, no. 1, pp. 62-67, 1983.

[9] O. Kazuyosi and I. Yosio, "Compressive strength of the CA mortar and its temperature-susceptibility," Memoirs of the Faculty of Technology, vol. 10, no. 2, pp. 1-13, 1976.

[10] F.-Z. Wang, Z.-C. Liu, T. Wang, and S.-G. Hu, “Temperature stability of compressive strength of cement asphalt mortar," $A C I$ Materials Journal, vol. 107, no. 1, pp. 27-30, 2010.

[11] Y.-L. Liu, X.-M. Kong, Y.-R. Zhang, and P.-Y. Yan, "Static and dynamic mechanical properties of cement-asphalt composites," Journal of Materials in Civil Engineering, no. 10, pp. 1489-1497, 2013.

[12] K.-C. Qiu, H.-S. Chen, H.-P. Ye, J.-X. Hong, W. Sun, and J.-Y. Jiang, "Thermo-mechanical coupling effect on fatigue behavior of cement asphalt mortar," International Journal of Fatigue, vol. 51, no. 6, pp. 116-120, 2013.

[13] H. Xu, P. Wang, X.-K. Wei, and X.-H. Zeng, "Dynamic compression damage experiment of CRTS I type CA mortar," Journal of Building Materials, vol. 17, no. 5, pp. 844-849, 2014 (Chinese).

[14] X.-J. Li and L.-H. Jiang, "Test and model parameter analysis of asphaltic sand with viscoelasticity," Journal of Wuhan University of Technology, vol. 33, no. 3, pp. 82-86, 2011 (Chinese).

[15] N.-S. Guo and Y.-H. Zhao, "Viscoelastic performance analysis of fiber reinforced asphalt concrete," Journal of Traffic and Transportation Engineering, vol. 7, no. 5, pp. 37-40, 2007 (Chinese).

[16] P. Wang, H. Xu, R. Chen, J. Xu, and X. Zeng, "Experimental research on compression properties of cement asphalt mortar due to drying and wetting cycle," Advances in Materials Science and Engineering, vol. 2014, Article ID 769248, 6 pages, 2014.

[17] Department of Science and Technology the Ministry of Railways, Provisional Technical Conditions of CRTS I Type Cement and Asphalt Mortar for Ballastless Slab Track in Passenger Dedicated Railway Line, 2008 (Chinese).

[18] P. Wang, H. Xu, and R. Chen, "Effect of cement asphalt mortar debonding on dynamic properties of CRTS II slab ballastless 
track," Advances in Materials Science and Engineering, vol. 2014, Article ID 193128, 8 pages, 2014.

[19] P.-G. Li, X.-Y. Liu, and G.-Q. Li, "Influence of CA mortar void on dynamic characteristics of unit slab track on bridge," China Railway Science, vol. 35, no. 3, pp. 20-27, 2014 (Chinese).

[20] Q.-Y. Xu, B. Li, and X.-L. Zhou, "Dynamic coefficient of slab track system on subgrade under high-speed trains," Journal of Central South University (Science and Technology), vol. 42, no. 9, pp. 2831-2836, 2011 (Chinese). 

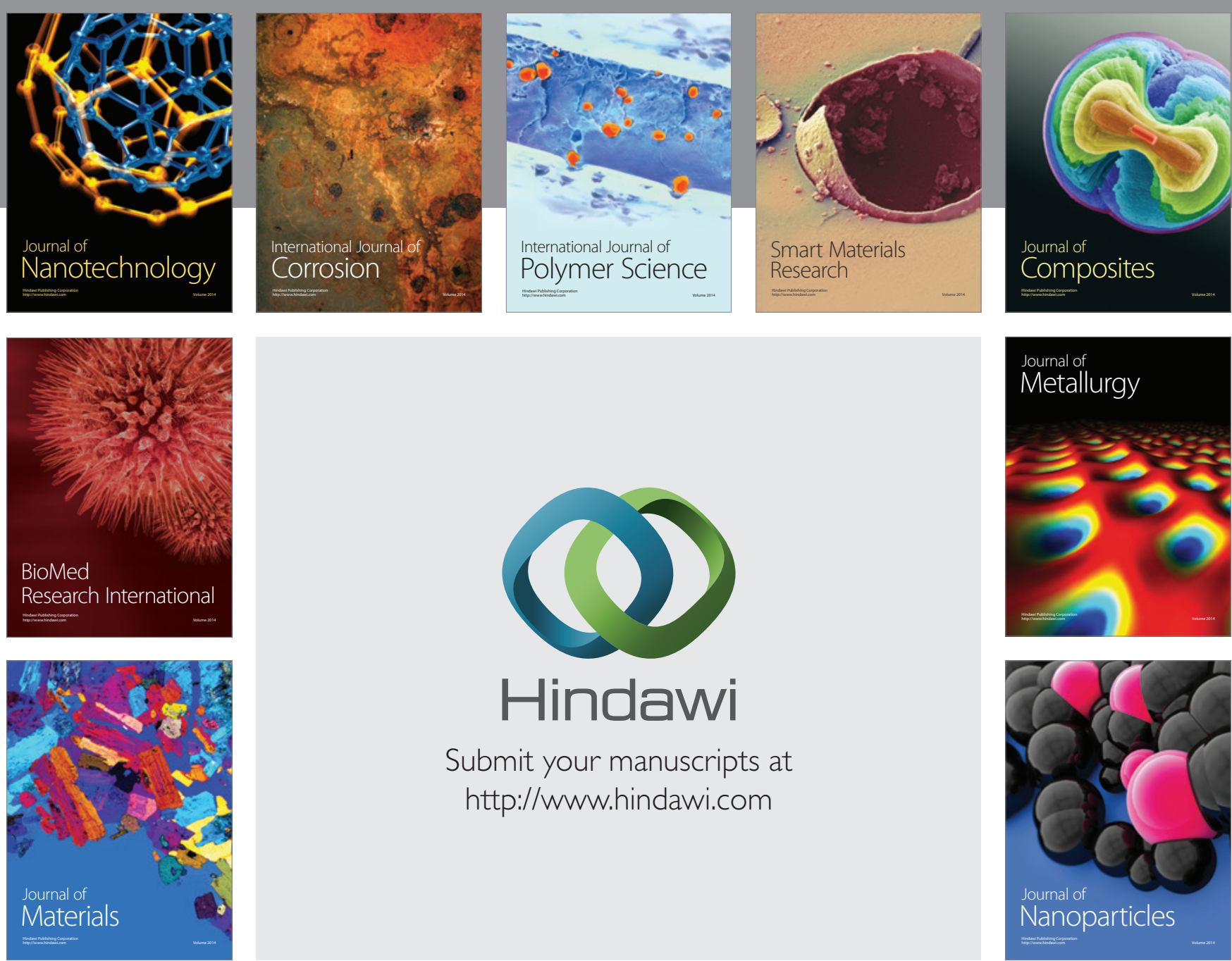

\section{Hindawi}

Submit your manuscripts at

http://www.hindawi.com

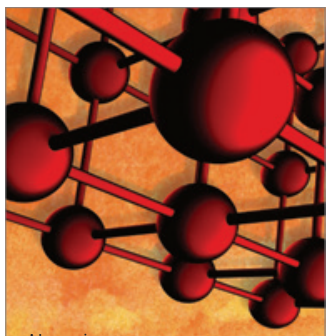

Materials Science and Engineering
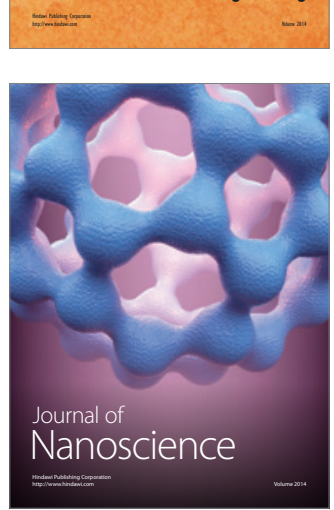
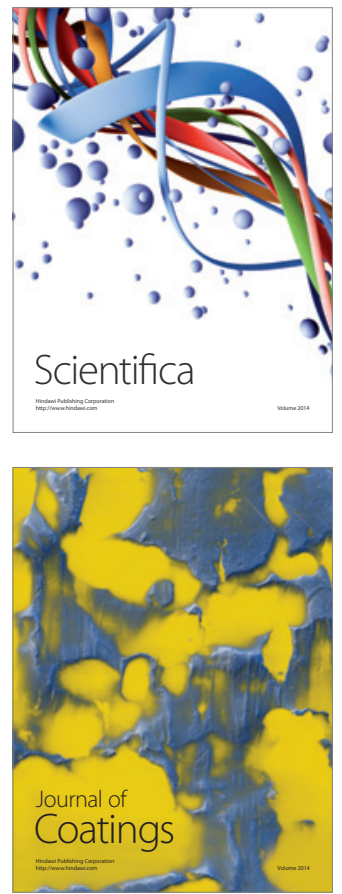
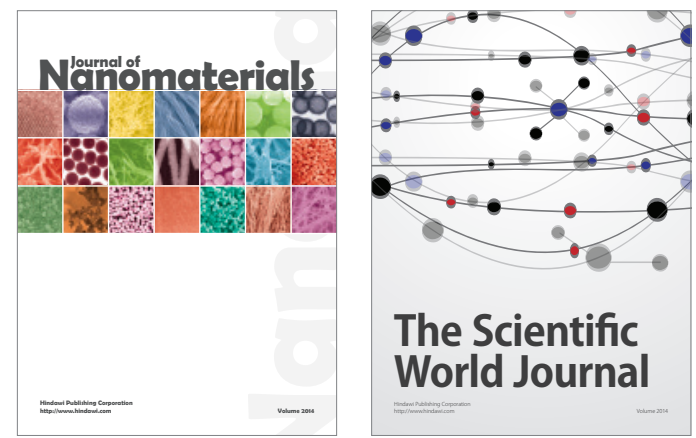

The Scientific World Journal
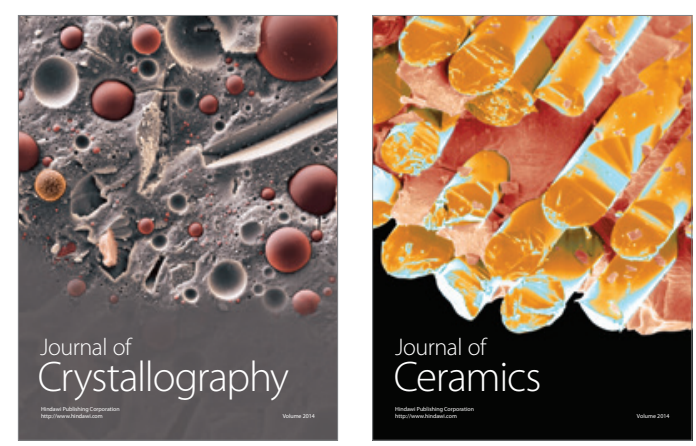
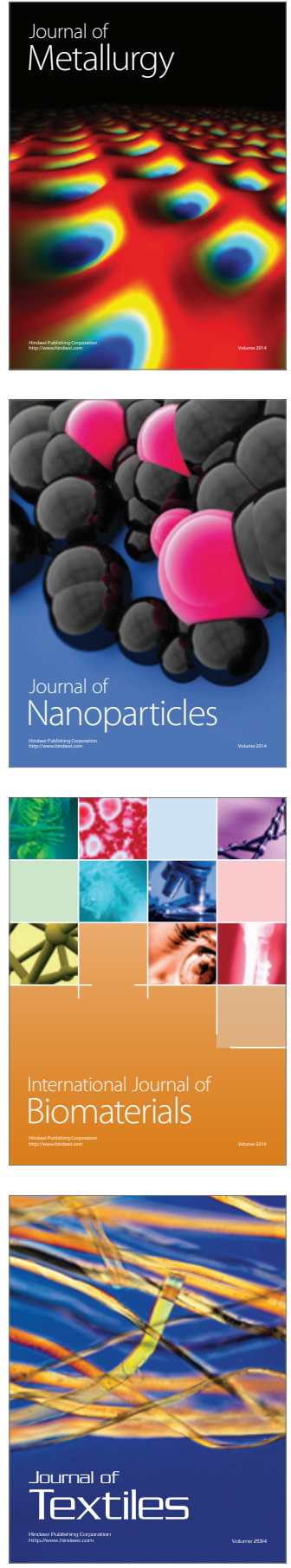